\title{
Drivers of peak sales for pharmaceutical brands
}

\author{
Marc Fischer • Peter S. H. Leeflang • \\ Peter C. Verhoef
}

Received: 20 January 2009 / Accepted: 28 July 2010 /

Published online: 13 August 2010

C The Author(s) 2010. This article is published with open access at Springerlink.com

\begin{abstract}
Peak sales are an important metric in the pharmaceutical industry. Specifically, managers are focused on the height-of-peak-sales and the time required achieving peak sales. We analyze how order of entry and quality affect the level of peak sales and the time-to-peak-sales of pharmaceutical brands. We develop a growth model that includes these two variables as well as control variables for own and competitive marketing activities. We find that early entrants achieve peak sales later, and they have higher peak-sales levels. High-quality brands achieve peak sales earlier, and their peak-sales levels are higher. In addition, quality has a moderating effect on the order of entry effect on time-to-peak-sales. Our results indicate that late entrants have longer expected time-to-peak-sales when they introduce a brand with high quality.
\end{abstract}

Keywords Peak-sales metrics · Brand growth · Econometric models · Market entry · Pharmaceutical marketing

JEL Classification C23 $\cdot$ C51 $\cdot$ L65 $\cdot$ M31

\footnotetext{
M. Fischer $(\triangle)$

Business and Economics,

e-mail: marc.fischer@uni-passau.de

P. S. H. Leeflang - P. C. Verhoef

P. S. H. Leeflang

e-mail: P.S.H.Leeflang@rug.nl

P. C. Verhoef

e-mail: p.c.verhoef@rug.nl

P. S. H. Leeflang

LUISS Guido Carli, Rome, Italy
}

University of Passau, Innstr. 27, 94032 Passau, Germany

Economics and Business, University of Groningen, P.O. BOX 800, 9700 AV Groningen, Netherlands 


\section{Introduction}

New products play a very important role in the pharmaceutical industry (Leenders and Wierenga 2008; Stremersch and van Dyck 2009). Pharmaceutical firms constantly introduce new drugs, and for these new drugs, peak sales represent an important metric, frequently used by investors to assess pharmaceutical firms' value (Obeid and Vine 2005; Suresh et al. 2006).

Peak sales can be characterized along two dimensions: the height-of-peak-sales and the time-to-peak-sales. Both metrics are closely related to new product performance such as cumulative sales. Intuitively, a brand with a higher level of peak sales is likely to have higher average sales over its life cycle. As a result, cumulative sales are also higher. Similarly, a brand with longer time-to-peak-sales enjoys a longer period of growth that contributes to accumulate sales and achieve a higher level of peak sales. Consequently, cumulative sales are again higher.

There are, however, exceptions to these rules. For example, a high level of peak sales may be achieved very fast. Although, we cannot rule out such a case theoretically, we do not believe it occurs often in reality because of restrictions to growth. Note that the growth rate needs to double if the same level of peak sales is to be achieved in half of the time. Firms can handle faster growth only up to a certain level due to supply and resource restrictions. In Appendix A, we also demonstrate that faster growth implies a higher variance of sales and therefore higher cash-flow volatility which is not desirable (Srivastava et al. 1998). Hence, even if demand might allow for a shorter time-to-peak sales, there are limits to growth from the supply side. The broad sample of new drugs that forms the basis of our empirical study supports our view. Time-to-peak-sales enhances height-of-peak sales and both peak-sales metrics increase cumulative brand sales. Together the two metrics explain more than $96 \%$ of observed variance in cumulative brand sales.

Time-to-peak-sales and height-of-peak-sales provide two important yardsticks that are easy to evaluate and predict even before launch. Assume management wants to assess the sales potential of a new product two years prior to launch. Cumulative sales may be obtained from the life cycle curve. Predicting the lifetime and sales for all periods, however, requires much more information than predicting only two peak-sales metrics. It is much easier to reach a consensus estimate for time-to-peak-sales and height-of-peak-sales. For pharmaceuticals, as an example, management can triangle information on the population size, the incidence of a disease and the reachable market share for the new drug to obtain an estimate for the height-of-peak-sales. Management would certainly use information on competitive entries, order of entry, marketing investment, etc. to predict the peak-sales metrics. Our empirical analysis provides important insights into the relevance of these variables for peak sales. Importantly, the analysis also suggests that those variables do not provide explanatory power for cumulative sales beyond the two peak-sales metrics. Hence, peak-sales metrics cannot simply be substituted by other predictors.

It is therefore not surprising that peak-sales metrics are widely adopted in practice, especially within the pharmaceutical industry. For example, Salix 
Pharmaceuticals reportedly has tumbled because its IBD franchise will "only achieve peak sales of \$ 99 million, lower than its previous estimate of \$ 135 million because of the Dec. 28 approval of three generic balsalazide (Colazal) formulations by the Food and Drug Administration" (Trading Markets.Com 2007). The importance of peak-sales metrics prompts business intelligence agencies such as IMS or Datamonitor to predict the peak sales of newly introduced drugs (e.g., Datamonitor 2007). Not only are the metrics important in practice (Obeid and Vine 2005), but scholars also acknowledge their relevance. For example, Bauer and Fischer (2000) and Schmid and Smith (2002) demonstrate that time-to- and height-of-peak-sales differ across brands introduced into different drug categories and countries due to factors such as order of entry.

In the marketing literature, there has been extensive attention to the role of order of entry and quality with regard to (new product) performance (Gielens and Dekimpe 2001; Kalyanaram and Urban 1992; Kalyanaraman and Wittink 1994; Robinson and Fornell 1985; Shankar et al. 1998). An important debate addresses the question whether first movers really have a competitive advantage as is often attributed to them (Golder and Tellis 1993; Kornelis et al. 2008; Zhang and Narasimhan 2000). Quite in contrast, recently Tellis and Johnson (2007) argue that delivering superior quality is considered as the most important driver of new product success. Hence, we assess the role of order of entry and quality for the market performance of a new drug in terms of peak sales.

The main objective of this study is to determine the drivers of height-of peaksales and time-to-peak-sales in the pharmaceutical industry. Through this study we contribute to the literature on new products and brand life cycles (Hauser et al. 2006), as this is the first study to investigate drivers of time-to- and height-of-peaksales. We show that some drivers differentially impact height-of-peak-sales and timeto-peak-sales. For example, marketing expenditures increase the level of peak sales, while they decrease the time-to-peak-sales. We aim to contribute to the literature on drivers of new product performance with a further investigation on the relative roles of order of entry, quality, and marketing efforts (see Tellis and Johnson 2007). Importantly, our results suggest that quality has by far the strongest positive effect on height-of-peak-sales, while it reduces the time-to-peak-sales. Finally, by executing this study in the pharmaceutical industry we also contribute to existing knowledge on pharmaceutical marketing (e.g. Kremer et al. 2008; Stremersch and van Dyck 2009).

The article is organized as follows: In the next section, we review the literature on drug life cycles and provide explanations why peak sales is a quite common phenomenon in the evolution of drug sales. Subsequently, we discuss potential drivers of time-to- and height-of-peak-sales and how they might affect the two metrics. We develop a model to measure the effects, then describe data from the pharmaceutical industry and discuss estimation issues. We follow up with a discussion of the empirical results. We continue with a cross-sectional analysis of new product performance to substantiate the relevance of the suggested metrics. In the final section, we conclude with research implications, limitations, and suggestions for further research. 


\section{Drug life cycles and peak sales}

\subsection{Life cycle research}

Studying the length and the shape of brand life cycles has a long history, including studies by Bauer and Fischer (2000), Brockhoff (1967), and Polli and Cook (1969). Research on specific metrics at the brand level in the development of the brand life cycle is scarce. Height-of-peak-sales and time-to-peak-sales have not been studied so far. Remarkably, studying the diffusion of article citations in Econometrica and the Journal of Econometrics, Fok and Franses (2007) model the time-to-peak citations and peak-citations of an article. Hence, though studied in a different context, there is academic attention for peak metrics in the econometric diffusion literature. We believe it is important to study such metrics in a new product context as well, as we will show that both these metrics are highly relevant for practice and they both are the most important determinants of cumulative brand sales.

Research at the product level has, however, investigated other specific metrics, as overviewed in Table 1. Several studies consider time-to-takeoff and subsequent growth of consumer durables (i.e., VCRs, televisions), as well as their drivers (Agarwal and Bayus 2002; Neelameghan and Chintagunta 2004; Golder and Tellis 1997; Stremersch and Tellis 2004; Tellis et al. 2003). Bayus (1998) specifically analyzes product lifetime as an important metric. Although these studies provide insights into which factors (i.e., economic, cultural) influence timeto-takeoff at the product level by country, they do not clarify the drivers at the brand level.

\subsection{Brand life cycles in drugs}

The development of demand for a new drug derives from both adoptions and repeats. For many drugs, the evolution of sales shows a peak. In Fig. 1, we depict the sales development of different brands in the French calcium channel blockers market. On the X-axis, we display the launch years of new drugs, and on the Y-axis, we provide annual sales for three entrants in this market. The figure clearly shows the occurrence of sales peaks. For example, the second entrant reaches its peak in 1988 with a sales level of approximately 200 million daily dosages.

The theories of adoption and imitation (Bass 1969) and informational cascades (Golder and Tellis 2004) explain why brand sales follows a life cycle. However, they are usually associated with the product level and first-time adoptions. Brand sales are, in addition, composed of repeat purchases, and they are subject to competition (Hahn et al. 1994).

Although some authors have questioned the transfer of the product life cycle concept to brands (Dhalla and Yuspeh 1976), brand life cycles have been reported quite frequently. The broadest evidence for brand life cycles is available for pharmaceuticals. Bauer and Fischer (2000), Corstjens et al. (2005), Cox (1967), Grabowski and Vernon (1990), Hahn et al. (1994), Lilien et al. (1981), Rao and Masataka (1988), and Simon (1979) all find strong evidence for the existence of a drug life cycle. In total, these researchers document the life cycles for more than 500 newly introduced drugs. 
Table 1 Overview of prior studies investigating specific metrics over a brand's/product's life cycle

\begin{tabular}{|c|c|c|c|c|}
\hline Study & Metrics & Data & Antecedents & Major findings \\
\hline $\begin{array}{l}\text { Golder and } \\
\text { Tellis } \\
(1997)\end{array}$ & $\begin{array}{l}\text { Time-to- } \\
\text { takeoff }\end{array}$ & $\begin{array}{l}\text { Aggregated sales by } \\
\text { category in the } \\
\text { U.S. }\end{array}$ & $\begin{array}{l}\text { Price, year of introduction, } \\
\text { market penetration }\end{array}$ & $\begin{array}{l}\text { - Average time-to-takeoff is } \\
\text { six years. } \\
\text { - At takeoff, price is } 63 \% \text { of } \\
\text { introductory price, and } \\
\text { penetration is } 1.7 \% \text {. } \\
\text { - Time-to-takeoff decreases } \\
\text { after World War II. }\end{array}$ \\
\hline $\begin{array}{l}\text { Bayus } \\
\quad(1998)\end{array}$ & $\begin{array}{l}\text { Product } \\
\text { lifetime }\end{array}$ & $\begin{array}{l}\text { Aggregated sales at } \\
\text { various product } \\
\text { market levels in the } \\
\text { U.S. PC industry }\end{array}$ & $\begin{array}{l}\text { Product introduction year, } \\
\text { firm entry year, } \\
\text { technology substitution }\end{array}$ & $\begin{array}{l}\text { - Product life cycles are not } \\
\text { shrinking over time. } \\
\text { - Observed acceleration in } \\
\text { life cycles is a result of } \\
\text { technology substitution. }\end{array}$ \\
\hline $\begin{array}{l}\text { Tellis et al. } \\
\text { (2003) }\end{array}$ & $\begin{array}{l}\text { Time-to- } \\
\text { takeoff }\end{array}$ & $\begin{array}{l}\text { Aggregated sales by } \\
\text { category for } \\
\text { different European } \\
\text { countries }\end{array}$ & $\begin{array}{l}\text { Economic and cultural } \\
\text { variables }\end{array}$ & $\begin{array}{l}\text { - Time-to-takeoff varies sub- } \\
\text { stantially across European } \\
\text { countries. } \\
\text { - Culture partially explains } \\
\text { country differences. } \\
\text { - Advantages for waterfall } \\
\text { strategy for international } \\
\text { product introduction. }\end{array}$ \\
\hline $\begin{array}{l}\text { Agarwal } \\
\text { and } \\
\text { Bayus } \\
(2002)\end{array}$ & $\begin{array}{l}\text { Time-to- } \\
\text { takeoff }\end{array}$ & $\begin{array}{l}\text { Aggregated sales by } \\
\text { category in the U.S. }\end{array}$ & $\begin{array}{l}\text { Price, new firm entry, } \\
\text { commercialization year }\end{array}$ & $\begin{array}{l}\text { - Takeoff in new firm entry } \\
\text { leads to sales takeoff. } \\
\text { - Firm entry dominates other } \\
\text { drivers of time-to-takeoff. }\end{array}$ \\
\hline $\begin{array}{l}\text { Stremersch } \\
\text { and } \\
\text { Tellis } \\
(2004)\end{array}$ & $\begin{array}{l}\text { Rate of } \\
\text { growth, } \\
\text { duration of } \\
\text { growth }\end{array}$ & $\begin{array}{l}\text { Aggregated sales by } \\
\text { category for } \\
\text { different European } \\
\text { countries }\end{array}$ & $\begin{array}{l}\text { Economic and cultural } \\
\text { variables }\end{array}$ & $\begin{array}{l}\text { - Growth metrics vary } \\
\text { substantially across } \\
\text { European countries. } \\
\text { - Economic factors primarily } \\
\text { explain country } \\
\text { differences. }\end{array}$ \\
\hline $\begin{array}{l}\text { Golder and } \\
\text { Tellis } \\
(2004)\end{array}$ & $\begin{array}{l}\text { Time-to- } \\
\text { takeoff, } \\
\text { slowdown, } \\
\text { duration of } \\
\text { growth }\end{array}$ & $\begin{array}{l}\text { Aggregated sales by } \\
\text { category in the U.S. }\end{array}$ & $\begin{array}{l}\text { Price, economic growth, } \\
\text { type of product, market } \\
\text { penetration }\end{array}$ & $\begin{array}{l}\text { - Slowdown occurs when } \\
\text { sales declines by about } \\
15 \% \text {. } \\
\text { - Probability of slowdown is } \\
\text { higher when economic } \\
\text { growth is slower, price } \\
\text { reductions are smaller, and } \\
\text { penetration is higher. } \\
\text { - Leisure-enhancing products } \\
\text { tend to have higher growth } \\
\text { rates and shorter growth } \\
\text { stages. }\end{array}$ \\
\hline This Study & $\begin{array}{l}\text { Time-to- } \\
\text { peak-sales, } \\
\text { height-of- } \\
\text { peak-sales }\end{array}$ & $\begin{array}{l}\text { Brand sales of } 45 \\
\text { pharmaceutical } \\
\text { brands in France, } \\
\text { Germany, Italy, and } \\
\text { UK }\end{array}$ & $\begin{array}{l}\text { Own marketing } \\
\text { expenditures, competitive } \\
\text { marketing expenditures, } \\
\text { order-of-entry, quality, } \\
\text { number of } \\
\text { competitors }\end{array}$ & $\begin{array}{l}\text { - Order of entry reduces time- } \\
\text { to-peak-sales and height- } \\
\text { of-peak-sales. } \\
\text { - Quality reduces time-to- } \\
\text { peak-sales and increases } \\
\text { height-of peak sales. } \\
\text { - A higher quality reduces the } \\
\text { negative effect of order of } \\
\text { entry on time-to-peak-sales. }\end{array}$ \\
\hline
\end{tabular}


Fig. 1 Illustration of peak sales in the French market for calcium channel blockers
Sales in mill. daily dosages

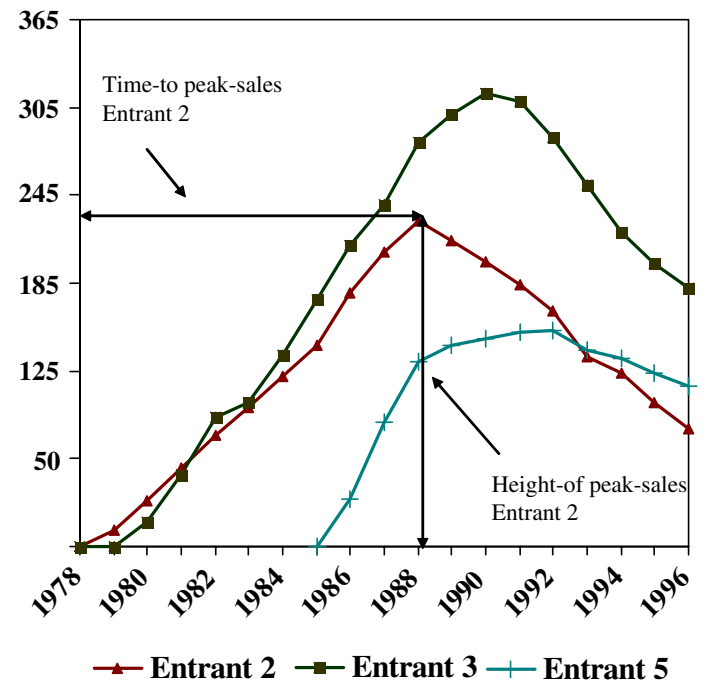

There are potentially several reasons why especially pharmaceuticals exhibit a peak in their sales trajectory. First, diffusion dynamics seem to be dominant for the evolution of (prescription) drug sales. Although refills have a large share in total drug sales, sales dynamics are predominantly driven by first-time prescriptions. This is simply due to the fact that physicians are reluctant to change a drug (i.e. the firsttime prescription) once it has been found to work for a patient, even in response to heavy marketing initiatives by competitor brands. As a result, researchers have adopted diffusion approaches to model drug sales with repeats where repeat rates are assumed constant (e.g., Hahn et al. 1994; Shankar et al. 1998). Second, pharmaceutical companies concentrate the bulk of their marketing efforts (i.e., detailing) on the first two years after launch, which causes an immediate strong increase in prescriptions but results in slower sales growth or even decline in later years when marketing support is only limited (Osinga et al. 2010). Third, by definition there is a limit in users of a drug as it is only relevant for patients with a specific treatment for a disease. Fourth, the entry of new competitors may inhibit sales growth to continue. These competitors may be other innovative drugs within the same or new categories, or generics after the patent has expired.

One might argue that instead of studying time-to- and height-of-peak-sales, one should study the time-to-takeoff metric (e.g. Tellis et al. 2003). As noted, this metric has been studied at the category level but not at the brand level. So far, there is no empirical evidence in the literature that this phenomenon occurs at the brand level, as well. We explored the available brand time-series but did not find evidence for a sales-takeoff phenomenon. Hence, beyond our substantive arguments there are also empirical arguments to study peak-sales metrics. 


\section{Variables affecting peak sales of pharmaceutical brands}

\subsection{Potential peak-sales drivers}

In this study, we focus on the impact of order of entry and quality on (1) the time-topeak-sales and (2) the height-of-peak-sales. We control for the effect of other, potentially relevant variables. Specifically, we consider own and competitive marketing support, the number of competitive entries into the market, the price of the drug, and marketing expenditures by co-marketing partners as control variables in the proposed brand sales model.

We define a pharmaceutical brand as a new chemical entity (NCE) marketed by a company in a specific country. Typically, innovative drugs enjoy patent protection for several years after launch. The competitive situation changes dramatically for an innovative drug when its patent expires and cheaper generic competitors rush into the market. In addition, innovative brands may be attacked by brands from other categories that offer alternative forms of drug treatment (technological substitution). Given that our data come from two categories that belong to the most innovative categories without generic price competition in our observation period, we focus on effects from competition among innovative prescription drugs within a category.

The sales evolution, and thus our focal metrics time-to-peak-sales and height-ofpeak-sales, is determined by four key metrics: the speed of adoption, the size of the adopter (patient) potential, the repurchase (refill) rate and the interpurchase time. For the majority of categories, repeat sales dynamics (interpurchase time and repurchase/ refill rate) are determined by exogenous factors such as therapy guidelines, patient characteristics, and physician skills. Physicians rarely risk switching the patient to another drug in response to marketing activities, because effectiveness and compatibility of the new drug are uncertain to a patient. Additionally, the time between refills follows medical needs for optimal treatment. As a consequence, we focus on the diffusion metrics speed of adoption and size of adopter potential in our discussion of order-of-entry and quality effects on peak sales as these decision variables do not change the repeat sales dynamics. Aggregate repeat sales metrics are constant over the life cycle of a drug unless therapy guidelines are replaced or the distributions of patient and physician characteristics change systematically (Hahn et al. 1994).

\subsection{Effects of order of entry and quality}

\subsubsection{Order of entry}

Multiple studies investigate the impact of order of entry on a brand's market share and sales (e.g., Kalyanaram et al. 1995; Robinson and Fornell 1985; Urban et al. 1986). Late entrants grow faster but achieve lower market share levels (Kalyanaram and Urban 1992). The effect has also been demonstrated for pharmaceuticals (Berndt et al. 1995; Shankar et al. 1998). These results are due to the fact that late-mover drugs face a lower adopter potential that is faster penetrated. In addition, late entrants 
are less effective than early entrants in competing for the remaining potential adopters (Kalyanaram and Urban 1992; Lieberman and Montgomery 1988). As a result, late entrants expect a lower level of peak sales and a shorter time-to-peak-sales. We note, however, that this effect may be moderated by other variables such as quality.

If late entrants penetrate the expected lower adopter potential at the same speed with similar support and quality as earlier entrants, time-to-peak-sales will be shorter. There are, however, good reasons to believe that their adoption speed is even faster than for early entrants. This is because buying resistance at the category level is much lower than it had been in earlier periods of the market life cycle. With more brands, consumers have had multiple opportunities to collect consumption experiences. Furthermore, social pressures on later adopters may favor trial probabilities for late mover brands (Bass 1969; Rogers 1995). The entry of another brand should not only increase brand variety but also enhance marketing activity in terms of pricing, advertising and promotion, which may lead to faster adoptions (Horsky and Simon 1983; Krishnan et al. 2000; Prins and Verhoef 2007). To summarize, we expect order of entry to reduce both the time-to-peak-sales and the height-of-peak-sales.

\subsubsection{Quality}

Quality is considered of essential importance for new product success (Tellis and Johnson 2007). There is no doubt that a better quality increases the attractiveness of the brand, which in turn should enlarge its adopter potential. Indeed, many studies demonstrate the positive sales effect of quality for drugs (Berndt et al. 1995). Hence, we expect a positive relation between the level of quality and the level of peak sales.

Adoption theory predicts that adoption will be faster for products with a relative quality advantage (Rogers 1995). Consequently, high-quality brands should face lower adoption barriers leading to a shorter time-to-peak-sales. The expected timeto-peak-sales should therefore decrease with quality. However, we have also argued that a better quality enlarges the adopter potential leading to a potentially longer time-to-peak-sales. If this effect is stronger than the accelerated adoption (trial) effect, we would expect a longer time-to-peak-sales for high-quality brands. As a consequence, we cannot provide a clear prediction about the direction of the (direct) quality effect and consider it as an empirical issue.

\subsubsection{Interaction between order of entry and quality}

Prior research has shown that the innovativeness of a new drug can reduce the disadvantage from being a late entrant (Shankar et al. 1998). The study of Shankar et al., however, focused on market share or brand sales, but not on peak-sales metrics. Hence, we cannot make any inference about the interaction effect between quality and order-of-entry with respect to the time-to-peak-sales. For time-to-peak-sales, we expect that a higher quality reduces the negative effect of a late entry on the time-topeak-sales. A product with better quality may provide the late entrant with more opportunities to gain prescriptions from competing incumbent brands. Low-quality late entrants won't be able to attract these prescriptions. As a consequence, the adopter potential for low-quality entrants will be lower and they achieve their peaksales earlier than high-quality late entrants. Quality thus reduces the negative impact 
of order of entry on time-to-peak-sales, i.e. we expect a positive interaction effect between quality and order of entry.

\subsection{Control variables}

\subsubsection{Own marketing support}

The amount of marketing support will affect the time-to- and height-of-peak-sales. Prior research shows that higher marketing expenditures speed up adoption (Gielens and Steenkamp 2007; Prins and Verhoef 2007; Steenkamp and Gielens 2003). Diffusion research demonstrates that higher marketing expenditures increase the diffusion rate and extend the market potential of adopters (Horsky and Simon 1983; Mahajan et al. 1990). Depending on which of these two effects is larger, the time-to-peak-sales will be shortened or extended. A recent meta-analysis (Kremer et al. 2008) shows that own marketing expenditures improve the sales base of a drug. Hence, we expect a positive effect of own marketing support on the height-of-peak-sales.

\subsubsection{Competitive marketing support}

Initially, we might predict that competitive marketing expenditures negatively affect the time-to-peak-sales. Prins and Verhoef (2007) show that competitive advertising reduces time to adoption. But competitive marketing efforts may also have a category-building effect that enhances both own and competitors' brand sales (Dubé and Manchanda 2005; Fischer and Albers 2010) and may extend the time-to-peaksales. As a consequence, it is difficult to provide a clear prediction about the effect of competitive marketing expenditures on time-to-peak-sales.

\subsubsection{Number of competitors}

The number of competitors in the market might also be relevant in explaining both time-to and height-of-peak-sales. The market share theorem (Cooper and Nakanishi 1988) postulates that a brand's market share is inversely related to the number of competitors in a market. The brand looses in relative attractiveness. The loss in attractiveness may have different sources. The memory-sequence effect (Alpert and Kamins 1994) or the variety seeking phenomenon (McAlister and Pessemier 1982) may explain the loss in attractiveness when more competitors are present in a market. We expect that the number of competitors reduces both the time-to-peaksales and the height-of-peak-sales.

\subsubsection{Price}

In the empirical application, we use a sample of firms and brands from four European countries (France, Germany, Italy, and the U.K.) during the period 19871996. The systems of health insurance and price regulation in these countries explain why pharmaceutical firms did not use price as a tactical marketing instrument in that period. In France and Italy, prices are determined exogenously by the respective 
authorities. In principle, launch prices can be set freely in the U.K. and Germany. Because drug expenses are typically reimbursed, demand is inelastic. As a result, firms have no incentive to reduce the price over time. Since a subsequent increase of the approved launch price would result in the loss of the reimbursement status, prices are also not raised in later periods and thus stay rather constant. Hence, price plays more or less the role of a cross-sectional control variable in this specific sample. Note also that we do not observe generic price competition in the sample.

\subsection{Summary}

We provide a summary of the expected effects of our included drivers of time-toand height-of-peak-sales in Table 2. In this table, we also report the operationalization of these variables, which we discuss in the next section in more detail. Finally, we note that we do not include distribution as predictor in our model (Kremer et al. 2008; Manchanda et al. 2005), as drug distribution in Europe is highly regulated, such that pharmacies are required by law to supply all approved prescription drugs.

\section{Data}

\subsection{Data sources}

We test our propositions using data from two prescription drug categories, calcium channel blockers and ACE inhibitors. These categories differ in their therapeutic principles for treating diseases such as hypertension or coronary heart disease. Data collected by IMS Health are available on a quarterly basis for a time period of 10 years (1987-1996) in each country. During that period, calcium channel blockers and ACE inhibitors represented the two largest (in monetary value) categories of cardio-vascular therapy. They offered the most advanced therapy alternatives for the treatment of hypertension, as an example, and substituted sales from established older categories such as diuretics or beta blockers. Lipid modifying agents (e.g., Lipitor) and A-II-inhibitors (e.g., Cozaar), which lead today's cardio-vascular drug prescriptions, were only available at the very end of the observation period.

The data include normalized (across different application forms) unit sales (transformed into daily dosages by a brand-specific dosage factor), daily dosage price and marketing spending, including expenditures on detailing ( $>90 \%$ of total spending), professional journal advertising and direct mailings. Sampling expenditures and other below-the-line activities (e.g., dinner invitations for physicians) are not covered. The data come from four European countries-France, Germany, Italy, and the United Kingdom - and comprise 73 brands in eight product markets (2 categories $\times 4$ countries). In addition, the data provide the month of product launch, a quality measure for each NCE and marketing expenditures by competitors and firms co-marketing the product, a frequently used method in this industry to enhance the diffusion of a new drug among physicians.

Both categories experienced multiple brand entries during the study period. The first calcium channel blocker was introduced in Germany in 1963 by Knoll, a German company which has been acquired by Abbott. The first ACE inhibitor was 
Table 2 Variable definition and expected direction of effects

\begin{tabular}{|c|c|c|c|}
\hline \multirow[t]{2}{*}{ Variable } & \multirow[t]{2}{*}{ Definition } & \multicolumn{2}{|c|}{ Expected Effect on ... } \\
\hline & & $\begin{array}{l}\text { Time-to-peak- } \\
\text { sales }\end{array}$ & $\begin{array}{l}\text { Height-of- } \\
\text { peak-sales }\end{array}$ \\
\hline Order of entry & $\begin{array}{l}\text { Count variable that counts the entry of NCEs into a } \\
\text { product market }\end{array}$ & - & - \\
\hline Quality & $\begin{array}{l}\text { Objective quality index based on evaluations of drug } \\
\text { quality in international meta-analytic review } \\
\text { reports (see Appendix B for details) }\end{array}$ & $+/-$ & + \\
\hline $\begin{array}{l}\text { Order of entry } \times \\
\text { quality }\end{array}$ & See above & + & N.A. \\
\hline \multicolumn{4}{|l|}{ Control variables } \\
\hline $\begin{array}{l}\text { Stock of own } \\
\text { marketing } \\
\text { expenditures }^{\mathrm{a}}\end{array}$ & $\begin{array}{l}M E S_{t}=\sum_{r=0}^{t}(1-\varphi)^{r} \operatorname{Exp}_{t-r}, \\
\text { where } \\
M E S_{t}=\text { Stock of own marketing expenditures at the } \\
\quad \text { end of quarter } t \\
\varphi=(\text { Estimated) quarterly depreciation rate } \\
\operatorname{Exp}_{t}=\text { Own marketing expenditures in quarter } t \\
\text { See also Berndt et al. }(1995,102)\end{array}$ & $+/-$ & + \\
\hline $\begin{array}{l}\text { Stock of competitive } \\
\text { marketing } \\
\text { expenditures }\end{array}$ & $\begin{array}{l}\text { Expenditures of all other brands (excluding co- } \\
\text { marketing partners) in a product market are } \\
\text { cumulated to produce competitive marketing } \\
\text { expenditures. The calculation of the stock follows } \\
\text { the approach as outlined under own marketing } \\
\text { expenditures. }\end{array}$ & $+/-$ & $+/-$ \\
\hline $\begin{array}{l}\text { Number of } \\
\text { Competitors }\end{array}$ & $\begin{array}{l}\text { Count variable that counts the number of NCEs that } \\
\text { have entered a product market in a specific quarter }\end{array}$ & - & N.A. \\
\hline
\end{tabular}

N.A.- Not estimated due to collinearity issues or data limitations

${ }^{\text {a }}$ To estimate the depreciation rate $\varphi$, we replace the stock variables in the brand sales model (Eq. 3) by quarterly marketing expenditures and add lagged sales to the predictor variables. The coefficient associated with the lagged dependent variable measures the carryover-coefficient (1- $\varphi$ ). To control for brand heterogeneity in this model, we specify a random brand constant that follows a normal distribution and estimate its mean and variance.

introduced in the United States and other countries in 1981 by Bristol Myers-Squibb. Additional countries followed quickly in both categories. Between 9 and 12 brands entered the country markets in each category, with most entries occurring during our observation period. Both categories experienced considerable growth in the 1980s, which slowed down or even turned into negative growth by 1996. The categories are comparable in their sales histories.

Even though the patent expired for a few early entrants in the calcium channel blocker category in the 1980s, intense generic competition did not evolve during our observed period. This is mainly due to the fact that cost containment issues did not play an important role in prescription behavior at that time. The market share of the few generic competitors is on average below $1 \%$. In addition, we observe that all innovative brands continued to grow after they lost patent protection, i.e. patent expiry does not coincide with time-to-peak-sales. 


\subsection{Measurement and descriptive statistics}

We adopt the slowdown measure by Golder and Tellis (2004) to determine each brand's time of peak sales and cross-validate this decision through visual inspections of the time series. 45 brands out of 73 brands reach their peak sales during the 10-year observation period. A few brand time series are left-truncated because they were launched before the start of the observation period. Thus, we have an unbalanced panel data set with 31 quarters per brand, on average, which we use to calibrate our model.

Our dataset shares a limitation with most previous studies on growth models. The data series are censored to the right. Hence, in a very strict sense, we cannot be absolutely sure that we observe the peak. It may just be a saddle phenomenon (Goldenberg et al. 2002), although that has not been documented for pharmaceutical brand sales so far. We therefore analyze the distribution of peak sales years and times-to-peak sales. We find that more than $60 \%$ of peak sales occurred three years before the end of the observation period or earlier. The distribution of peak-sales years follows a normal distribution $(p>.05)$. Additionally, we find that for $80 \%$ of the brands time-to-peak-sales amounts to four years or longer. Hence, we have much confidence that our data are representative of the peak sales phenomenon in the analyzed categories. We also test the robustness of the results later when we change the composition of the sample to eliminate left truncation issues, as an example.

In Table 3, we summarize information about the time-to- and height-of-peak-sales for the 45 brands. The average time-to-peak-sales for calcium channel blockers is higher because of the very early introduction of the pioneer in all countries that we investigate. In several cases, early entrants continue to grow after later entrants already have achieved their peak. We also note that the time of the category sales peak does not necessarily coincide with the time when brand sales peak. Hence, the time-to-peak in terms of category demand appears to be independent of the time-topeak in brand demand.

We provide means and standard deviations of other key variables for the 45 brands in Table 3. The height-of-peak-sales is slightly more than four times greater than the average brand sales in both categories.

Time-to-peak-sales and height-of-peak-sales are correlated with .424. As expected, the association is positive, i.e. a longer time-to-peak-sales helps accumulating sales and achieving a higher level of peak sales. We also correlate our two focal measures with the cumulative (unit) sales and approximated cumulative discounted cash flows (DCF). The correlations of height-of-peak-sales with cumulative sales and discounted cash flows are .981 and .935 , respectively. Correlations are smaller but still sizeable with respect to time-to-peak-sales: .470 (cumulative sales) and .336 (cumulative DCF). In Section 7 we will further elaborate on the relationships of the peak-sales metrics with cumulative sales and cumulative DCF.

The operationalization of the quality index deserves special attention. We adopt an objective quality index based on international medical evaluation standards (for a similar approach, see Venkataraman and Stremersch 2007). This index measures the objective quality of each NCE along seven equally weighted dimensions that capture the breadth of application, efficacy, convenience, and pharmaco-kinetic performance of the drug. Specifically, the dimensions are the number of approved indications, number of interactions, frequency of side effects, frequency of medication, protein 
Table 3 Descriptive statistics (45 brands, 1,386 observations)

\begin{tabular}{|c|c|c|c|c|c|}
\hline & \multirow[t]{2}{*}{$\begin{array}{l}\text { Variation over } \\
\text { time }^{\mathrm{a}}\end{array}$} & \multicolumn{2}{|c|}{$\begin{array}{l}\text { Calcium channel } \\
\text { blockers }\end{array}$} & \multicolumn{2}{|c|}{ ACE inhibitors } \\
\hline & & Mean & $\begin{array}{l}\text { Standard } \\
\text { deviation }\end{array}$ & Mean & $\begin{array}{l}\text { Standard } \\
\text { deviation }\end{array}$ \\
\hline Time-to-peak-sales (in years) & Time-invariant & 9.69 & 8.10 & 6.37 & 3.74 \\
\hline $\begin{array}{l}\text { Height-of-peak-sales (in mill. daily } \\
\text { dosages per quarter) }\end{array}$ & Time-invariant & 81.02 & 90.71 & 60.11 & 56.28 \\
\hline $\begin{array}{l}\text { Brand sales (in mill. daily dosages per } \\
\text { quarter) }\end{array}$ & Time-varying & 19.29 & 20.08 & 14.00 & 12.75 \\
\hline Market share (in daily dosages) & Time-varying & .12 & .14 & .13 & .14 \\
\hline Order of entry & Time-invariant & 4.71 & 2.77 & 4.43 & 2.68 \\
\hline Quality & Time-invariant & .98 & .19 & 1.01 & .09 \\
\hline Time in market (years) & Time-varying & 10.78 & 8.53 & 5.60 & 3.86 \\
\hline Price (in $\$$ per daily dosage) & Time-varying & .52 & .27 & .72 & .18 \\
\hline Number of competitors in product market & Time-varying & 8.37 & 2.33 & 7.81 & 2.36 \\
\hline $\begin{array}{l}\text { Stock of own marketing expenditures per } \\
\text { quarter (in mill. \$) }\end{array}$ & Time-varying & 1.70 & 1.43 & 2.20 & 1.31 \\
\hline $\begin{array}{l}\text { Stock of co-marketing expenditures per } \\
\text { quarter (in mill. } \$)^{\mathrm{b}}\end{array}$ & Time-varying & 1.31 & 1.28 & 1.36 & .98 \\
\hline $\begin{array}{l}\text { Stock of competitive marketing } \\
\text { expenditures per quarter (in mill. \$) }\end{array}$ & Time-varying & 19.51 & 8.83 & 20.67 & 9.24 \\
\hline
\end{tabular}

${ }^{a}$ Note that time-varying variables that enter the time-to-process function (4) are used as time-invariant variables, measured in the year when peak sales occurred

${ }^{\mathrm{b}}$ For cases in which co-marketing agreements exist

absorption, plasma half-lifetime, and bioavailability (for details see Appendix B including Table 8).

\section{Econometric model and estimation}

\subsection{Brand-growth model}

Bertalanffy (1957) proposes a generalized mathematical theory of growth that encompasses many long-term growth models discussed in the marketing literature. The idea behind that theory is that growth processes can be formalized by a general differential equation that represents the antagonism of progress and decay. Diffusion models such as the Bass (1969) model derive from that theory and have found wide application in marketing. Several limitations of the Bass model, however, prevent its use for our data. The model focuses on the category level and explains first-time adoptions of a new product (Mahajan et al. 1990). We need to model sales at the brand level that is composed of both adoptions and repeat purchases. We note that there are a few extensions of the Bass model that apply to brand diffusion and incorporate repeat purchases (e.g., Hahn et al. 1994; Krishnan et al. 2000). These 
models, however, require accounting for competitor diffusion and repeat dynamics that increase model complexity, especially if many brands are to be analyzed as in our study. In addition, the Bass model assumes a growth process that is for the most part symmetric around the time of peak sales. ${ }^{1}$ Previous research suggests that drug sales follow an asymmetric life cycle (e.g., Bauer and Fischer 2000). A parametric growth model that derives from Bertalanffy's general theory but is not subject to these limitations is Brockhoff's (1967) model. It assumes an asymmetric growth path that leads to a single peak in a brand's lifetime. Consistent with this growth model, we specify sales of brand $i$ in (calendar) period $t$ as follows ${ }^{2}$ :

$$
s_{i t}=m_{i} \cdot L C T_{i t}^{a_{i}} \cdot e^{-b_{i} L C T_{i t}} \cdot g\left[\mathbf{Z}_{i t}\right], \quad m_{i}, a_{i}, b_{i}>0,
$$

where

$s_{i t} \quad$ Sales of brand $i$ in period $t$

$m_{i} \quad$ Brand-specific scaling constant

$L C T_{i t} \quad$ Elapsed time since market introduction of brand $i$ in (calendar) period $t$

$a_{i}, b_{i} \quad$ Brand-specific growth parameters and

$g\left[\mathbf{Z}_{i t}\right] \quad$ A multiplier shifting sales depending on the $\mathbf{Z}$-vector of relevant predictors of brand $i$ in period $t$.

This model has several desirable properties. For example, if we differentiate Eq. 1 with respect to $L C T$ and set the expression equal to 0 , we obtain an expression for the time-to-peak-sales, $\psi_{i}=\frac{a_{i}}{b_{i}}$, and thus

$$
a_{i}=b_{i} \psi_{i}
$$

\subsection{Brand sales model}

Following Ainslie et al. (2005), we insert Eq. 2 into (1). We introduce $k$ for category, $l$ for country, specify the variables in $\mathbf{Z}$ explicitly, and take the logarithm of sales to derive an equation that is linear in response parameters. We then arrive at:

$$
\begin{aligned}
& \ln s_{k l i t}= \ln m_{k l i}+b_{k l i} \psi_{k l i} \ln L C T_{k l i t}-b_{k l i} L C T_{k l i t}+\beta_{1} \ln O E_{k l i}+\beta_{2} \ln Q_{k l i}+\beta_{3} \ln P R C_{k l i t} \\
&+\gamma_{1 k l i} \ln M E S_{k l i t}+\gamma_{2 k l i} \ln C o m M E S_{k l i t}+\gamma_{3 k l i} \ln C o M E S_{k l i t}+\sum_{h=1}^{H-1} \delta_{h l} S D_{h l t} \\
&+v_{k}+\tau_{l}+\omega_{k l}+u_{k l i t}, \\
& \text { with } v_{k} \text { i.i.d. } N\left(0, \sigma_{v}^{2}\right), \tau_{l} \text { i.i.d. } N\left(0, \sigma_{\tau}^{2}\right), \omega_{k l} \text { i.i.d. } N\left(0, \sigma_{\omega}^{2}\right), u_{k l i t} \text { i.i.d. } N\left(0, \sigma_{u}^{2}\right), \\
& m_{k l i}=\bar{m}+\eta_{k l i} \text { and } \eta_{k l i} \text { i.i.d. } N\left(0, \sigma_{\eta}^{2}\right), b_{k l i}=\bar{b}+v_{k l i} \text { and } v_{k l i} \text { i.i.d. } N\left(0, \sigma_{v}^{2}\right), \\
& \psi_{k l i}=\bar{\psi}+\mu_{k l i} \text { and } \mu_{k l i} \text { i.i.d. } N\left(0, \sigma_{\mu}^{2}\right), \gamma_{k l i}=\bar{\gamma}+\lambda_{k l i} \text { and } \lambda_{k l i} \text { i.i.d. } N(\mathbf{0}, \boldsymbol{\Lambda}),
\end{aligned}
$$

where:

$O E_{k l i}$

$Q_{k l i}$

Order of entry of brand $i$ in category $k$ and country $l$

Quality of brand $i$ relative to the average in category $k$ and country $l$

\footnotetext{
${ }^{1}$ Let $t^{\text {Peak }}$ be the period of peak sales. Then, sales evolves symmetrically within the interval $\left[t^{\text {Peak }}-2 t^{\text {Peak }}\right.$, $\left.t^{\text {Peak }}+2 t^{\text {Peak }}\right]$ (Mahajan et al. 1990).

2 The corresponding Bertalanffy differential equation is $\frac{d s_{i}}{d L C T_{i}}=a_{i} \frac{1}{L C T_{i}} s_{i}-b_{i} s_{i}$, with $a_{i}, b_{i}>0$.
} 


\begin{tabular}{|c|c|}
\hline$P R C_{\text {klit }}$ & Price of brand $i$ in category $k$, country $l$, and period $t$ \\
\hline$M E S_{k l i t}$ & $\begin{array}{l}\text { Stock of own marketing expenditures of brand } i \text { in category } k \text {, } \\
\text { country } l \text {, and period } t\end{array}$ \\
\hline ComMES $S_{\text {klit }}$ & $\begin{array}{l}\text { Stock of marketing expenditures by brand } i \text { 's competitors } \\
\text { (excluding co-marketing partners) in category } k \text {, country } l \text {, and } \\
\text { period } t\end{array}$ \\
\hline CoMES $_{\text {klit }}$ & $\begin{array}{l}\text { Stock of marketing expenditures by pharmaceutical companies } \\
\text { that co-market brand } i \text { in category } k \text {, country } l \text {, and period } t\end{array}$ \\
\hline $\begin{array}{l}S D_{h l t} \\
m, \psi, b, \beta, \gamma, \delta\end{array}$ & $\begin{array}{l}\text { Seasonal dummy variable for quarter } h \text { in country } l \text { and period } t \\
\text { (Unobserved) parameter vectors }\end{array}$ \\
\hline$v, \tau, \omega, u, \sigma^{2}$ & Error terms and error variances \\
\hline$k$ & $1, K=2$ (number of categories) \\
\hline$l$ & $1,2, . ., L=4$ (number of countries) \\
\hline$i$ & $1,2, \ldots, I_{k l}$ (number of brands per category and country) \\
\hline$t$ & $1,2, \ldots, T_{i}$ (number of observation periods per brand); and \\
\hline$h$ & $1,2, ., H=4$ (number of quarters). \\
\hline
\end{tabular}

Recall that a product market is defined as category by country. The terms $\eta_{k l i}, v_{k l i}$, $\mu_{k l i}$, and $\lambda_{k l i}$ denote brand-specific deviations of heterogeneous parameters from their mean $(\bar{m}, \bar{b}, \bar{\psi}$, and $\bar{\gamma})$ across product markets and brands, assumed to be drawn from a normal distribution with 0 mean and constant variance. In this way, we account for heterogeneous effects that facilitate the pooling of the cross-sectional and time-series data. We do not model $\beta_{1}$ and $\beta_{2}$ as heterogeneous because these parameters are associated with time-independent variables. Although in theory, it is possible to identify heterogeneous parameters from purely cross-sectional information, it remains a challenging task in real data sets (Bodapati and Gupta 2004). This logic also applies to $\beta_{3}$, the parameter associated with price. Although price is fundamentally a timevarying quantity, we observe almost no time variation in our data supporting our view that it was not used as a marketing instrument by firms. Here, we treat price as a cross-sectional control variable. The model also includes a brand-specific scaling constant $\left(m_{k l i}\right)$ that controls for unobserved brand-specific effects, such as brand equity, that are assumed to be randomly distributed across brands.

We follow Berndt et al.'s (1995) approach for measuring the stock of pharmaceutical marketing expenditures, and find a quarterly carryover coefficient of .540 (see Table 2 for more details). We test whether the carryover coefficient differs for the two product categories but find no significant differences. By including marketing stock variables, we account for sales dynamics that are typical for new drugs due to inertia and diffusion effects. The stock of competitive marketing expenditures reflects the impact of competitors' marketing campaigns on own brand sales. We include the stock of comarketing expenditures to account for the impact of co-marketing deals between pharmaceutical firms. The brand sales model accommodates possible seasonal fluctuations in drug demand by country according to quarterly dummy variables.

Finally, the model shows a nested, multilevel error structure which consists of error components that are category-specific, $v_{k}$, country-specific, $\tau_{l}$, and product-marketspecific, $\omega_{k l}$. We assume these errors and the idiosyncratic error, $u_{k l i t}$, to be uncorrelated. As a result, the error variance is $\operatorname{Var}\left(v_{k}+\tau_{l}+\omega_{k l}+u_{k l i t}\right)=$ $\sigma_{v}^{2}+\sigma_{\tau}^{2}+\sigma_{\omega}^{2}+\sigma_{u}^{2}$. With this error structure, we account for differences in market 
size between categories, countries, and product markets. In addition, this specification implies that errors are contemporaneously correlated across categories within a country, across countries within a category, and across brands within a product market.

\subsection{Time-to-peak-sales model}

The brand sales model (Eq. 3) includes the time-to-peak-sales, $\psi_{k l i}$, as an unobserved heterogeneous parameter that can be decomposed into a mean and a random component. We extend this specification and allow the mean to be shifted by the following cross-sectional variables:

$$
\begin{aligned}
\psi_{k l i}= & \alpha_{0}+\alpha_{1} O E_{k l i}+\alpha_{2} Q_{k l i}+\alpha_{3} O E_{k l i} \times Q_{k l i}+\alpha_{4} \ln M E S_{k l i, t_{i}^{P E A K}} \\
& +\alpha_{5} \ln \operatorname{ComMES}_{k l i, t_{i}^{P E A K}}+\alpha_{6} \ln N C_{k l i, t_{i}^{P E A K}}+\zeta_{k l i},
\end{aligned}
$$

where $t_{i}^{P E A K}$ denotes the calendar year in which a brand achieved its peak sales, $N C$ denotes the number of competitors in a product market, $\zeta$ is an i.i.d. error term uncorrelated with the error terms of Eq. 3, and all other terms are defined as previously. We take the log of the number of competitors, and of own and competitive marketing stock to account for diminishing returns, measured at the time the brand reaches its peak sales. Order of entry and quality, which are time-invariant, get measured at the time of launch. Note that $t_{i}^{P E A K}$ measures calendar time that is unrelated to $\psi_{k l i}$, a duration variable (correlation coefficient $=-.171, p>.10$ ). Hence, there are no endogeneity concerns arising from time of measurement.

\subsection{Estimation}

Equations 3 and 4 establish a multi-level regression model. We estimate the model using the simulated maximum likelihood technique that was also used by Fok and Franses (2007). Under the usual regularity conditions, the estimator is consistent and asymptotically normal distributed.

\subsection{Elasticities}

When we differentiate Eq. 4 with respect to the predictors of interest, we obtain the marginal time-to-peak-sales effect of that variable, which we can easily transform into an elasticity-based measure. To derive the height-of-peak-sales effects, we substitute Eq. 4 into 3 and differentiate the expression with respect to the predictor variable of interest (see Appendix $\mathrm{C}$ for details). The formal expressions for the time-to- and height-of-peak-sales elasticities appear in Table 4. Because order of entry and number of competitors are non-continuous variables, we must interpret their elasticity with care. Before we discuss the estimation outcomes we elaborate on endogeneity issues.

\subsection{Endogeneity issues}

Our model includes several strategic variables that may be endogenous. For example, because pharmaceutical firms decide about the timing of product launch, 
Table 4 Definition of peak-sales effects (elasticities)

\begin{tabular}{lll}
\hline & \multicolumn{2}{l}{ Relative change in $\ldots$} \\
\cline { 2 - 3 } Due to relative change in ... & Time-to-peak-sales & Height-of-peak-sales \\
\hline Order of entry & $\frac{\left(\alpha_{1}+\alpha_{3} \bar{Q}\right) \overline{O E}}{\overline{L C T}^{P E A K}}$ & $\bar{b}\left(\alpha_{1}+\alpha_{3} \bar{Q}\right) \ln \overline{L C T}^{P E A K} \overline{O E}+\beta_{1}$ \\
Quality & $\frac{\left(\alpha_{2}+\alpha_{3} \overline{O E}\right) \bar{Q}}{\overline{L C T}^{P E A K}}$ & $\bar{b}\left(\alpha_{2}+\alpha_{3} \overline{O E}\right) \ln \overline{L C T}^{P E A K} \bar{Q}+\beta_{2}$ \\
Stock of own marketing expenditures & $\frac{\alpha_{4}}{\overline{L C T}^{P E A K}}$ & $\bar{b} \alpha_{4} \ln \overline{L C T}^{P E A K}+\bar{\gamma}_{1}$ \\
Stock of competitive marketing expenditures & $\frac{\alpha_{5}}{\overline{L C T}^{P E A K}}$ & $\bar{b} \alpha_{5} \ln \overline{L C T}^{P E A K}+\bar{\gamma}_{2}$ \\
Number of competitors & $\frac{\alpha_{6}}{\overline{L C T}^{P E A K}}$ & - \\
\hline
\end{tabular}

A bar over the variable indicates the mean. Order of entry and number of competitors are treated as continuous variables to derive the elasticity measure. See Appendix C for details

product quality, and the level of marketing investment taking (past) sales into account, failing to account for endogeneity can lead to biased or inconsistent parameter estimates (Franses 2005). We executed Wu-tests to assess whether the exogeneity assumption is violated for our included variables (Greene 2004). These tests show that (1) order of entry $(O E)$, (2) quality $(Q)$, (3) long-term marketing investment until time-to-peak-sales $\left(M E S_{t^{P E A K}}\right)$, and (4) the number of competitors $\left(N C_{t^{P E A K}}\right)$ are indeed endogenous $(p<.01)$. The Wu-test shows that the exogeneity assumption with respect to competitive marketing expenditures $(p>.05)$ and comarketing expenditures $(p>.05)$ is not violated. Hence, we estimate a reduced-form model and employ instrumental variables estimation with exogenous information that identifies the firm's strategic variables (Franses 2005) for the four variables $O E$,

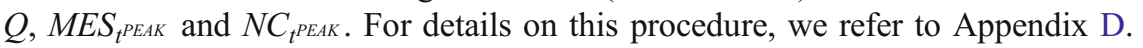

One alternative way to deal with endogeneity issues would be to model firm interactions in an equilibrium framework (e.g., Chintagunta et al. 2006). Given the long time horizon of 10-12 years required to develop a new drug and the uncertainties associated with the outcomes of clinical trials and the approval process, an appropriate model would feature the solution to a dynamic stochastic game among 8 to 10 firms that decide about entry timing, quality, and long-term marketing investments. Such a model is beyond the scope of this paper.

\section{Estimation results}

\subsection{Model fit}

We present the estimation results for the brand-sales model applied to the eight product markets in Table 5. Model fit is very good. To assess the in-sample and outof-sample fit, we exclude the last four quarters of year 1996 from estimation. Squared correlation between predicted and actual values of the dependent variable amount to .969 in the estimation sample (1,206 observations) and .941 in the hold- 
Table 5 Estimation results for the brand sales model (Eqs. 3 and 4)

\begin{tabular}{|c|c|c|c|}
\hline & & $\begin{array}{l}\text { Parameter } \\
\text { estimate }\end{array}$ & $\begin{array}{l}\text { Estimated SD of } \\
\text { parameter distribution }\end{array}$ \\
\hline Scaling constant & $\ln m$ & $6.31(.164)$ & $.000(.009)^{\mathrm{NS}}$ \\
\hline \multicolumn{4}{|l|}{ Time-to-peak-sales process function } \\
\hline Constant & $b \times \alpha_{0}$ & $2.44(.219)$ & \\
\hline Order of entry $^{\mathrm{a}}$ & $b \times \alpha_{1}$ & $-.373(.024)$ & \\
\hline Quality $^{\mathrm{a}}$ & $b \times \alpha_{2}$ & $-1.83(.151)$ & \\
\hline Order of entry $\times$ quality $^{\mathrm{a}}$ & $b \times \alpha_{3}$ & $.354(.021)$ & \\
\hline $\log (\text { stock of own marketing expenditures })^{\mathrm{a}}$ & $b \times \alpha_{4}$ & $.077(.016)$ & \\
\hline Log(stock of competitive marketing expenditures) & $b \times \alpha_{5}$ & $.020(.015)^{\mathrm{NS}}$ & \\
\hline $\log (\text { no. of competitors within product market })^{\mathrm{a}}$ & $b \times \alpha_{6}$ & $-.184(.033)$ & \\
\hline Error standard deviation & $\sigma_{\mu}$ & $.145(.151)^{\mathrm{NS}}$ & \\
\hline \multicolumn{4}{|l|}{ Brand sales function } \\
\hline Elapsed time since launch (growth constant) & $b$ & $.096(.004)$ & $.119(.004)$ \\
\hline $\log (\text { order of entry })^{\mathrm{a}}$ & $\beta_{1}$ & $-.589(.030)$ & \\
\hline $\log (\text { quality })^{\mathrm{a}}$ & $\beta_{2}$ & $2.49(.235)$ & \\
\hline $\log ($ price $)$ & $\beta_{3}$ & $-.321(.022)$ & \\
\hline $\log$ (stock of own marketing expenditures) & $\gamma_{1}$ & $.346(.007)$ & $.087(.002)$ \\
\hline Log(stock of competitive marketing expenditures) & $\gamma_{2}$ & $-.155(.019)$ & $.054(.001)$ \\
\hline Log(stock of co-marketing expenditures) & $\gamma_{3}$ & $.012(.005)$ & $.051(.003)$ \\
\hline $\begin{array}{l}\text { Category-specific error component } \\
\text { (standard deviation) }\end{array}$ & $\sigma_{v}$ & $.013(.012)^{\mathrm{NS}}$ & \\
\hline $\begin{array}{l}\text { Country-specific error component } \\
\text { (standard deviation) }\end{array}$ & $\sigma_{\tau}$ & $.002(.010)^{\mathrm{NS}}$ & \\
\hline $\begin{array}{l}\text { Product-market-specific error component } \\
\text { (standard deviation) }\end{array}$ & $\sigma_{\omega}$ & $.010(.009)^{\mathrm{NS}}$ & \\
\hline Log Likelihood & & -495.10 & \\
\hline No. of brands & & 45 & \\
\hline No. of observations & & 1,386 & \\
\hline
\end{tabular}

Standard errors in parentheses. Estimated seasonal effects are not reported and may be obtained from the authors. NS $=$ not significant $(p>.05)$

${ }^{\text {a }}$ Instrumental variables used.

out sample (180 observations). ${ }^{3}$ Table 5 includes the estimated means and standard deviations of the distributions for heterogeneous parameters. All estimates for which we explicitly predict the direction of the effect show the expected sign.

We also check for serial correlation in the error term but do not find evidence for it. The autocorrelation coefficient is $.048(p=.605)$. Note that sales dynamics are

\footnotetext{
${ }^{3}$ The model fit may appear unusually high for a panel data set. It reflects, however, the extensive selection of predictors and specification of brand heterogeneity in the constant and slope parameters which finally leads to a model that adapts to the specifics of each individual brand time-series. Note that $\mathrm{R}^{2}$ for a simple OLS model with homogenous coefficients already amounts to .808 reflecting the strong explanatory power of the selected predictor variables.
} 
implicit to the definition of our stock variables (see Table 2 again). In addition, we explicitly model growth dynamics in Eq. 1 .

\subsection{Model comparison}

In the existing literature, there are several competing sales growth models including diffusion models and parametric growth models. We compare the selected model with alternative parametric growth models that can be derived from Bertalanffy's growth theory. Specifically, we consider the model used by Shankar et al. (1999) for pharmaceuticals and a model that represents a symmetric sales evolution and is comparable to the Bass model. According to the Bayesian Information Criterion, the model turned out to be inferior $\left(-1,455.8_{\text {proposed }}\right.$ vs. $-1,592.0_{\text {symmetric }}$ vs. $-1,594.5_{\text {Shankar et al. }}$. The squared correlations of predicted and actual values of the citerion variables in the estimation and holdout samples also appear to be lower (.900/.886 for the symmetric model and $.961 / .936$ for the Shankar et. al. model). Hence, we conclude that for our data, Brockhoff's model best represents the brand growth process. ${ }^{4}$

Another alternative model is the one suggested by Fok and Franses (2007), which represents an extension of the Bass model (see also Boswijk and Franses 2005). As noted earlier, their model studies time-to-peak-citations and peak citations. Specifically, they propose a multi-level regression model to measure determinants of these two citation metrics. Our model is similar to theirs as we also propose a multi-level regression model using the same estimation technique (simulated maximum likelihood). Our model is, however, more parsimonious as we only have one second-level equation, while their approach requires estimating four of such equations. Importantly, the Fok and Franses diffusion model is specified in terms of cumulated brands sales, which we do not observe for brands earlier than the start of our observation period. Although we cannot use the full sample, we calibrate and compare the extended Bass model with our suggested model in a reduced sample of 26 brands (635 observations). Since both models are calibrated on different sets of criterion and predictor variables a direct comparison in terms of fit measures is not possible. We therefore apply the Davidson/McKinnon-test (see e.g., Greene 2004). The idea of this test is to use the predicted values of the alternative model as an additional predictor adding potentially relevant new information to the focal model. The test is inconclusive for our data, i.e. the two models are not superior to each other. The advantage of our proposed model is, however, that it can be applied to the full sample.

\subsection{Time-to-peak-sales process function}

We find a negative main effect of order of entry on time-to-peak-sales $\left(\alpha_{1}=-.373\right.$, $p<.05)$, indicating that later entrants achieve their peak sales earlier, consistent with our expectation. This result also complements previous findings regarding the

\footnotetext{
${ }^{4}$ We also checked whether the brand time-series show multiple peaks by visual inspection. The phenomenon occurs at the quarterly level due to short-term sales fluctuations. Aggregated to the annual level, sales evolution appears much smoother indicating a single peak.
} 
impact of order of entry on brand growth (Kalyanaram and Urban 1992). The main effect of quality is negative, which implies that a quality improvement reduces timeto-peak-sales $\left(\alpha_{2}=-1.83, p<.05\right)$; we proposed arguments in favor of both directions. The interaction effect between quality and order of entry, however, is positive $\left(\alpha_{3}=.354, p<.05\right)$. That is, a higher quality limits the negative effect of order of entry on time-to-peak-sales. The total effect of a change in entry order (quality) for a brand, given a certain quality (entry order position), can be assessed by calculating the elasticities of Table 4 (see Section 6.5.1).

We find a positive impact of the stock of own marketing expenditures on time-topeak-sales $\left(\alpha_{4}=.077, p<.05\right)$. The effect of the stock of competitive marketing expenditures is not significant $\left(\alpha_{5}=.020, p>.05\right)$. Consistent with our expectation, we find a negative time-to-peak-sales effect for the number of competitors within the market $\left(\alpha_{6}=-.184, p<.05\right)$.

\subsection{Brand sales level}

Consistent with prior research, we find a significant negative direct impact of order of entry on sales $\left(\beta_{1}=-.589, p<.05\right)$. The estimated value is close to its generalized value of -.50 (Kalyanaram et al. 1995). Quality has a strong and positive influence on sales $\left(\beta_{2}=2.49, p<.05\right)$, in support of our expectation. For price, we find a negative but inelastic coefficient, which confirms our expectation $\left(\beta_{3}=-.321\right.$, $p<.05)$. Recall that in our dataset price mainly varies across cross sections. We also find a positive impact of the stock of own marketing expenditures on sales $\left(\gamma_{1}=.346\right.$, $p<.05)$ but a negative effect of the stock of competitive marketing expenditures $\left(\gamma_{2}=-.155, p<.05\right)$. Finally, the impact of the stock of co-marketing expenditures on sales is positive and significant $\left(\gamma_{3}=.012, p<.05\right)$. These marketing expenditure variable estimates refer to average effects. The large standard deviation associated with the effect of co-marketing activities reveals that some brands suffer from cannibalization effects (i.e., $\gamma_{3 k l i}<0$ for some $i$ ).

\subsection{Estimated peak-sales elasticities}

\subsubsection{Time-to-peak-sales elasticities}

Following Table 4, we compute peak-sales effects in terms of elasticities to make results comparable across variables. Recall that these estimates are not directly available from the parameter estimates of the brand sales model in Table 5 and may differ across brands. We report the average effect over all brands in our sample. As we show in Table 6, the elasticities of time-to-peak-sales with respect to order of entry $(=-.126, p<.05)$ and quality $(=-.264, p<.05)$ are negative. That is, for the average brand, an increase in these variables reduces the time until it reaches peak sales. The elasticity of quality is greatest in terms of absolute value; this result is based on the average order-of-entry position in our data, which is between 4 and 5 . The stock of own marketing expenditures depicts a positive time-to-peak-sales elasticity $(=.099, p<.05)$. Hence, for the average brand, marketing investments prolong the time span until peak sales. Finally, we find a significant negative elasticity of time-to-peak-sales associated with the number of competitors in the 
Table 6 Estimated peak-sales elasticities (evaluated at sample means)

\begin{tabular}{lll}
\hline & \multicolumn{2}{l}{ Relative Change in $\ldots$} \\
\cline { 2 - 3 } Due to Relative Change in $\ldots$ & Time-to-peak-sales & Height-of-peak-sales \\
\hline Order of entry & $-.126(.025)$ & $-.796(.284)$ \\
Quality & $-.264(.116)$ & $2.06(.305)$ \\
Stock of own marketing expenditures & $.099(.022)$ & $.507(.031)$ \\
Stock of competitive marketing expenditures & $.025(.019) \mathrm{NS}$ & $-.114(.031)$ \\
Number of competitors & $-.235(.036)$ & N.A. \\
\hline
\end{tabular}

N.A.- Not estimated due to collinearity issues or data limitations

Approximated standard errors in parentheses. Note that the effects for order of entry and quality are total effects and account for the interaction effect. NS $=$ not significant $(p>.05)$

market $(=-.235, p<.05)$. The elasticity of the stock of competitive marketing expenditures is not significant $(=.025, p>.05)$.

\subsubsection{Height-of-peak-sales elasticities}

Quality elasticity is greatest in absolute value $(=2.06, p<.05)$, followed by the negative order-of-entry elasticity $(=-.796, p<.05)$ and the positive elasticity with respect to the stock of own marketing expenditures $(=.507, p<.05)$. Note, however, that the elasticity of the actual expenditure level, which is required to achieve a certain stock level, is lower. Multiplying the stock elasticity by the estimated depreciation factor $\widehat{\varphi}=.460$, we obtain a value of .233 . Competitive marketing activity has the smallest effect on height-of-peak-sales but is nevertheless substantial $(=-.114, p<.05)$. In summary, quality, order of entry, and own marketing expenditures emerge as significant drivers of the height-of-peak-sales, underlining the importance of these strategic variables in the pharmaceutical industry.

\subsection{Robustness}

We perform several analyses to check the robustness of our findings. First, we investigate the robustness of the results against collinear influences, focusing on order of entry, quality, and their interaction. To determine whether multicollinearity has a destabilizing influence on the parameter estimates, we regress $O O E, Q$, and $O O E \times Q$ on either $O O E$ or $Q$ or both of them. The residuals from these regressions alternatively might be used in model estimation (Hill and Adkins 2003). The consistent and collinearity-free estimates confirm the results reported in Table 5. Note that we need to exclude the number of competitors and the interaction of order of entry with quality from the brand sales equation due to collinearity issues. Using the above described procedure, we obtain collinearity-free estimates for these variables that are consistent with our expectation.

Second, we check whether our results may be driven by the composition of the sample by applying the model to five new samples. The first sample consists only of brands launched during our observation period, which eliminates the issue of left 
truncation. In the second sample, we eliminate the pioneer brand to control for a possible sample bias that might arise from the long lead time of the pioneer. In the third and fourth samples, we apply more conservative rules to classify brands that have passed their peak sales, leading to reduced sizes of 40 and 36 brands, respectively. The last sample contains all 73 brands, including brands that have not achieved peak sales yet. In this case, we must exclude the stock of own and competitive marketing expenditures from the process function in Eq. 4 because we do not observe these quantities for all brands. The results do not change substantially, which underlines the robustness of our findings.

Third, we regress observed time-to- and height-of-peak-sales on our focal drivers in a cross-sectional regression that covers the 45 brands of our sample (see also Section 7 and Table 7). We find significant effects for several drivers, consistent with our results from the full model. Note that these cross-sectional regressions test the effects on peak-sales metrics without making any assumptions about the functional form of the growth model, which provides evidence that our results are not driven by the type of growth model.

Fourth, we check whether the model improves if we include quality dimensions separately or use an unbalanced weighting scheme for the composite measure. We do not find evidence for model improvement. We also check to what extent results change if we define quality as a time-varying measure by dividing the quality index of a brand by the average quality of all competitors in the market. Results are very stable. This is because quality is by large a cross-sectional phenomenon in our data. Cross-sectional variation accounts for $92 \%$ in total variance for the time-varying quality measure.

\section{Cross-sectional analysis of new product performance}

A basic premise of this article is that the two suggested peak sales metrics are highly relevant for explaining new product success in the pharmaceutical industry. In this section, we test whether this premise holds for the 45 brands in our sample. For that purpose, we regress cumulative brand (unit) sales and cumulative discounted brand cash flows (DCF) as measures of new product performance on the two peak-sales metrics and their drivers. In addition, we analyze the drivers of time-to- and heightof-peak-sales in this cross-sectional setting.

We subtract the marketing expenditures from revenues and discount them by a quarterly rate of $3 \%(\approx 12.5 \%$ per annum) to obtain discounted cash flows (DCF). Marginal costs for new pharmaceuticals are usually very low accounting for only 10$15 \%$ of revenues. They do not vary much across brands and time. The most important sources of variation are revenues and marketing expenditures which are available to us.

Table 7 shows the results of the four cross-sectional regressions. Standard errors are White-corrected to account for cross-sectional heteroskedasticity (Greene 2004) and endogenous variables are instrumented as reported earlier. We discuss first results for the two peak-sales metrics. Specifications are consistent with Eqs. 3 and 4. By definition, the dynamic brand sales function produces the height-of-peak-sales by including time-to-peak-sales into the vector of arguments (see Appendix C again). Hence, it is part of the predictor set for the height-of-peak-sales regression in Table 7. 


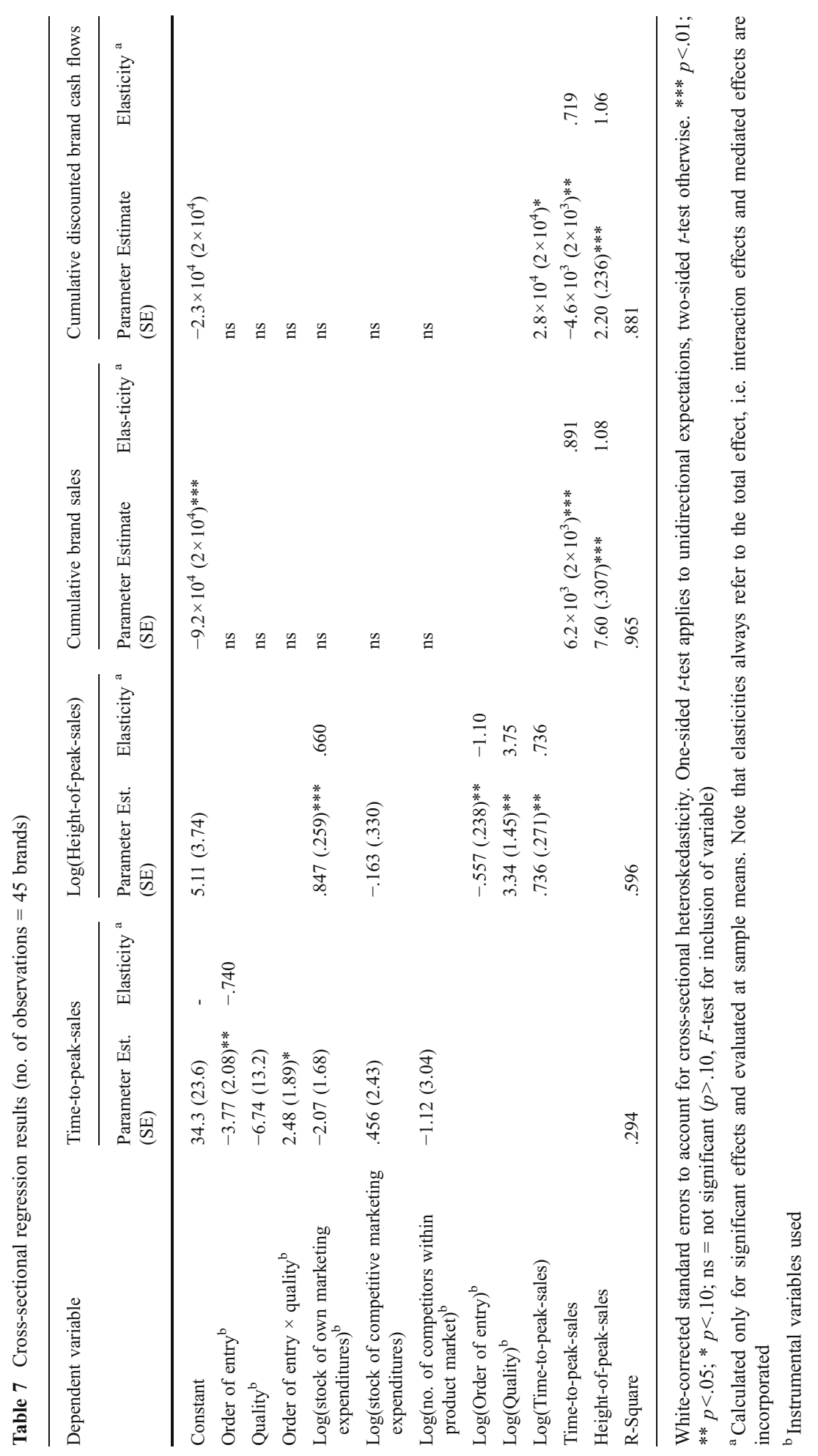


Overall, the results strongly support the findings of Table 5. We note, however, that most of the coefficients related to the time-to-peak-sales drivers do not achieve significance. The small sample size of 45 observations together with five instrumented predictors suggests that the statistical power is not very high. The situation is less critical for height-of-peak-sales as dependent variable. Here, we find a significant positive influence of time-to-peak-sales (elasticity of .736). Note that this finding cannot be driven by the type of growth function because we do not specify any growth function.

The last two columns of Table 7 show the results with respect to cumulative brand sales and cumulative DCF. The findings impressively suggest that both peak-sales metrics are highly relevant predictors of new product success. $\mathrm{R}^{2}$ is as high as .965 for cumulative brand sales and .881 for cumulative DCF. Moreover, we find that none of the driver variables such as order of entry, quality, etc. add explanatory power above and beyond the peak sales metrics. Hence, we find strong evidence for our basic premise of the relevance of peak-sales metrics.

While time-to-peak-sales has a positive direct and indirect (via height-of-peaksales) impact on cumulative brand sales it should also have an opposite effect on cumulative DCF due to time discounting. To separate these effects we include the $\log$ of time-to-peak-sales in that regression and indeed find a non-monotonic, inverted U-relationship. Based on the estimates, the turning point occurs only after several years suggesting that the negative discounting effect is not large enough to offset the positive impact of time-to-peak-sales on new product performance.

\section{Conclusions, limitations, and future research}

We suggest two new metrics of new product performance: time-to-peak-sales and height-of-peak-sales. Our empirical analysis provides strong evidence for the power of these metrics to explain the performance of new drugs. By developing a brand sales growth model, we simultaneously model the effect of order of entry, quality, and control variables on time-to- and height-of-peak-sales. The estimation results provide interesting insights. Order of entry impacts both time-to- and height-of-peak-sales. More specifically, early entrants achieve peak-sales later, and they have higher peaksales levels. Quality is also an important driver of peak-sales. High-quality brands achieve peak sales earlier. In addition, higher quality is associated with a higher level of peak sales. We also study the moderating effect of quality on the order-of-entry effect on time-to-peak-sales. Our results indicate that late entrants have longer expected time-to-peak-sales when they introduce a brand with high quality. Or stated differently, quality limits the negative effect of order of entry on time-to-peak-sales. One explanation for this finding is that due to the higher quality the late entrant is able to attract customers from early entrants increasing its adopter potential which in turn requires more time to be penetrated resulting in a longer time-to-peak-sales. Together these findings thus support the available notions in the literature that both order of entry and quality are important drivers of new product success.

Our results also shed some further light on the discussion on which decision variable is more important, order of entry or quality (Tellis and Johnson 2007). Our results suggest that both variables are important, as they offer the largest elasticities for 
time-to- and height-of-peak-sales compared to other variables such as competitive entries. However, peak-sales elasticities with respect to quality are even higher than for order of entry. This observation complements the finding on the dominant role of quality for firm value (Tellis and Johnson 2007). However, more research is warranted to study the important trade-off between quality and order of entry.

Our study is also subject to limitations. The estimation results hold for two (related) categories of pharmaceuticals. It would be interesting to extend the analysis to other pharmaceutical categories and even other industries. In addition, we cannot generalize our findings to alternative growth model specifications. A regression of observed times-to-peak sales on our focal variables, which is not subject to specific assumptions about the growth model, finds similar results. Hence, we have much confidence that our results do not suffer from this limitation. Future research, however, should investigate to what extent peak-sales metrics are influenced by specific assumptions about the growth model.

Although we analyze the effects of several important variables such as order of entry, quality, and marketing support, we do not claim they are the only important predictors of the time-to- and height-of-peak-sales. More research should investigate the role of other variables. The level of retail support for over-the-counter drugs might be an excellent candidate in this respect. If more data were available researchers could also extend the analysis to cover total brand lifetime. Finally, in this study we specifically focused on peak-sales as a key metric at the brand level. Studying other metrics goes beyond the focus of our investigation.

Acknowledgements We are grateful to Abbot Laboratories Germany (previously Knoll AG) for providing the data used in this research. We thank Sönke Albers, Tammo Bijmolt, Michel Clement, and Kent Nakamoto and participants at the 2003 Marketing Science Conference in Maryland, Research Camp on Pharmaceutical Marketing, University of Groningen 2005, and the UCLA and USC faculty seminars for helpful comments on previous versions of this article. We acknowledge the helpful and supportive comments of the editor and reviewers.

We also are indebted to Dick Wittink, who contributed to a previous version. Dick passed away unexpectedly on June 4, 2005.

Open Access This article is distributed under the terms of the Creative Commons Attribution Noncommercial License which permits any noncommercial use, distribution, and reproduction in any medium, provided the original author(s) and source are credited.

\section{Appendix A}

Sales volatility and growth

Assume we observe product sales $s$ from launch until $t=T^{*}$, the period when sales reach their maximum level. Assume further that sales evolve at an annual compound sales growth rate $g$. Denoting the sales level in the launch year $(t=0)$ with $k$, we can describe sales evolution in terms of the starting level $k$ and the annual compound growth rate $g$. Cumulative sales at $t=T^{*}$ are given by

$$
\sum_{t=0}^{T^{*}} s_{t}=\sum_{t=0}^{T^{*}} k(1+g)^{t} \text {, with } k \geq 0 \text { and } g \geq 0 .
$$


Note that the mean $E\left[s_{t}\right]=\mu$ of the sales time-series, $s_{0}, s_{1}, \ldots, s_{t}, \ldots, s_{T^{*}}$, is defined as

$$
\mu=\frac{1}{1+T^{*}} \sum_{t} k(1+g)^{t}
$$

Intuitively, the average sales level should be higher the higher the growth rate, which can be shown by differentiating (A.2) with respect to $g$

$$
\frac{d \mu}{d g}=\frac{1}{1+g} k \frac{1}{1+T^{*}} \sum_{t} t(1+g)^{t}>\text {. }
$$

We can demonstrate that the variance in sales as a measure of volatility increases in the growth rate. Let us decompose the variance of sales into

$$
\operatorname{Var}\left(s_{t}\right)=E\left[s_{t}^{2}\right]-\mu^{2}
$$

Because $\operatorname{Var}\left(s_{t}\right)>0$, it follows $E\left[s_{t}^{2}\right]>\mu^{2}$ and we can write for (A.4)

$$
\operatorname{Var}\left(s_{t}\right)=r \mu^{2}-\mu^{2}, \text { with } r=\frac{E\left[s_{t}^{2}\right]}{\mu^{2}}
$$

Differentiating (A.5) with respect to $g$ gives

$$
\frac{d \operatorname{Var}\left(s_{t}\right)}{d g}=2(r-1) \frac{d \mu}{d g}
$$

Since $r>1$ and $d \mu / d g>0$, expression (A.6) is always greater than zero. Hence, the larger the sales growth is the larger the sales volatility. If the same level of peak sales is reached in shorter time, the volatility in sales must increase.

\section{Appendix B}

Definition of the quality measure

Two healthcare professionals who work in the pharmaceutical industry compiled the data for each quality dimension for each drug from published international drug review reports. These reports are like meta-analysis reports, in that they collect combined evidence about the seven quality dimensions from studies published primarily in academic journals and summarize them. The performance measure of a drug uses different units for different dimensions: percentage (bioavailability, protein absorption), hours (plasma half-lifetime), and frequency (average occurrence of side effects, number of interactions, number of indications, dosage per day). Side effects, interactions, and required dosage are reverse coded. The efficacy dimensions, bioavailability, protein absorption, and plasma half-time relate positively to efficacy, so there are no code reversals for these dimensions. The same applies to the number of indications.

The performance of a drug on each quality dimension is transformed into a value that represents its performance relative to the mean performance of all drugs in its category on that dimension. For each drug, the relative values of quality are 
Table 8 Measurement of quality dimensions

\begin{tabular}{|c|c|c|c|}
\hline Quality dimension & Measurement & Notation & Transformation \\
\hline Bioavailability & In $\%(100 \%=$ full bioavailability $)$ & $X_{1}$ & $\begin{array}{l}\text { No } \\
\text { transformation }\end{array}$ \\
\hline Protein absorption & In $\%(100 \%=$ full absorption $)$ & $X_{2}$ & $\begin{array}{l}\text { No } \\
\text { transformation }\end{array}$ \\
\hline Plasma half-lifetime & In hours & $X_{3}$ & $\begin{array}{l}\text { No } \\
\text { transformation }\end{array}$ \\
\hline Number of indications & $\begin{array}{l}\text { Counts the number of approved indications } \\
\text { for the drug }\end{array}$ & $X_{4}$ & $\begin{array}{l}\text { No } \\
\text { transformation }\end{array}$ \\
\hline $\begin{array}{l}\text { Frequency of side } \\
\text { effects }\end{array}$ & Average occurrence of side effects in $\%$ & $X_{5}$ & $X_{5}^{\prime}=1 / X_{5}$ \\
\hline Number of interactions & Counts the number of dangerous drug interactions & $X_{6}$ & $X_{6}^{\prime}=1 / X_{6}$ \\
\hline Dosage & Counts the number of intakes of medicine per day & $X_{7}$ & $X_{7}^{\prime}=1 / X_{7}$ \\
\hline
\end{tabular}

aggregated across all dimensions to provide an overall quality index for that drug. The final results are cross-validated by two leading doctors at a reputed university hospital. Table 8 provides the exact measurement approach for each dimension.

Let $\bar{X}_{1}, \bar{X}_{2}, \bar{X}_{3}, \bar{X}_{4}, \bar{X}_{5}^{\prime}, \bar{X}_{6}^{\prime}$, and $\bar{X}_{7}^{\prime}$ denote the mean across all drugs within a category. The quality measure is then defined by taking the average of the relative drug performance across the seven dimensions, i.e. $Q=\frac{1}{7}\left(\frac{X_{1}}{\bar{X}_{1}}+\frac{X_{2}}{\bar{X}_{2}}+\frac{X_{3}}{\bar{X}_{3}}+\frac{X_{4}}{\bar{X}_{4}}+\frac{X_{5}^{\prime}}{\bar{X}_{5}^{\prime}}+\frac{X_{6}^{\prime}}{\bar{X}_{6}^{\prime}}+\frac{X_{7}^{\prime}}{\bar{X}_{7}^{\prime}}\right)$.

\section{Appendix C}

\section{Derivation of peak-sales elasticities}

The time-to-peak-sales and height-of-peak-sales effects in Table 4 are derived according to the method described below. Without loss of generality, we demonstrate the derivation with respect to order of entry. We calculate the effect for the average brand in our sample; mean values are indicated with a bar over the variable.

(1) Time-to-peak-sales elasticity

For ease of exposition, we omit the brand, category, country, and time subscripts. We define the time-to-peak-sales effect of order of entry as the change in time-topeak-sales due to a change in the order of entry. We treat order of entry as a continuous variable. Hence, we take the first derivative of Eq. 4 with respect to $O E$ :

$$
\frac{\partial \psi}{\partial O E}=\alpha_{1}+\alpha_{3} \bar{Q}
$$

To express Eq. C.1 in terms of an elasticity measure, $\varepsilon_{\psi, O E}$, we multiply it by $\overline{O E} / \bar{\psi}$ :

$$
\varepsilon_{\psi, O E}=\frac{\left(\alpha_{1}+\alpha_{3} \bar{Q}\right) \overline{O E}}{\bar{\psi}}
$$


Note that we do not estimate the parameters $\alpha_{1}$ and $\alpha_{3}$ directly but rather estimate their product with the average growth parameter (after substituting Eq. 4 into 3). Define $c_{1}=\bar{b} \alpha_{1}$ and $c_{3}=\bar{b} \alpha_{3}$. Because we estimate $c_{1}, c_{3}$, and $\bar{b}$, we can apply the delta method to obtain the standard error for expression (C.2):

$$
\operatorname{SE}\left(\varepsilon_{\psi, O E}\right)=\left[\begin{array}{l}
\frac{1}{\bar{b}^{2}} \operatorname{Var}\left(c_{1}\right)+\frac{\left(c_{1}+c_{3} \bar{Q}\right)^{2}}{\bar{b}^{4}} \operatorname{Var}(\bar{b})+\frac{\bar{Q}^{2}}{\bar{b}^{2}} \operatorname{Var}\left(c_{3}\right) \\
-\frac{2\left(c_{1}+c_{3} \bar{Q}\right)}{\bar{b}^{3}} \operatorname{Cov}\left(c_{1}, \bar{b}\right)-\frac{2 \bar{Q}\left(c_{1}+c_{3} \bar{Q}\right)}{\bar{b}^{3}} \operatorname{Cov}\left(c_{3}, \bar{b}\right)+\frac{2 \bar{Q}}{\bar{b}^{2}} \operatorname{Cov}\left(c_{1}, c_{3}\right)
\end{array}\right]^{1 / 2}\left(\frac{\overline{O E}}{\psi}\right)
$$

(2) Height-of-peak-sales elasticity

Define $L C T=\psi$ in Eq. 3, substitute Eq. 4 into this expression, and differentiate with respect to $O E$ :

$$
\begin{aligned}
\frac{1}{s^{P E A K}} \frac{\partial s^{P E A K}}{\partial O E} & =\bar{b} \frac{\partial \psi}{\partial O E} \ln \bar{\psi}+\frac{\bar{b} \bar{\psi} \frac{\partial \bar{\psi}}{\partial E}}{\overline{L C T}}-\bar{b} \frac{\partial \bar{\psi}}{\partial O E}+\frac{\beta_{1}}{O E} \\
& =\bar{b} \frac{\partial \bar{\psi}}{\partial O E} \ln \bar{\psi}+\frac{\beta_{1}}{O E} .
\end{aligned}
$$

Substitute Eq. C. 1 into C.4 and multiply by $s^{P E A K}$ to obtain the marginal effect:

$$
\frac{\partial s^{P E A K}}{\partial O E}=\left[\bar{b}\left(\alpha_{1}+\alpha_{3} \bar{Q}\right) \ln \bar{\psi}+\frac{\beta_{1}}{\overline{O E}}\right] \bar{s}^{P E A K}
$$

Multiplying Eq. C.5 by $\overline{O E} / \bar{s}^{P E A K}$ gives the elasticity measure in Table 4:

$$
\varepsilon_{S^{P E A K}, O E}=\bar{b}\left(\alpha_{1}+\alpha_{3} \bar{Q}\right) \ln \bar{\psi} \overline{O E}+\beta_{1}
$$

Given that $\bar{b} \alpha_{1}=c_{1}, \bar{b} \alpha_{3}=c_{3}, \bar{b}$, and $\beta_{1}$ are directly estimated, Eq. C.6 is a linear combination of random variables, and a standard error estimate is readily available:

$$
S E\left(\varepsilon_{S^{P E A K}, O E}\right)=\left\{\begin{array}{l}
{\left[\operatorname{Var}\left(c_{1}\right)+\bar{Q}^{2} \operatorname{Var}\left(c_{3}\right)\right](\overline{O E} \ln \bar{\psi})^{2}+2 \bar{Q} \overline{O E} \ln \bar{\psi} \operatorname{Cov}\left(c_{1}, c_{3}\right)} \\
+\operatorname{Var}\left(\beta_{1}\right)+2 \overline{O E} \ln \bar{\psi} \operatorname{Cov}\left(c_{1}, \beta_{1}\right)+2 \bar{Q} \overline{O E} \ln \bar{\psi} \operatorname{Cov}\left(c_{3}, \beta_{1}\right)
\end{array}\right\}^{1 / 2}
$$

\section{Appendix D}

Procedure of instrumental variables estimation

Our instrumental variables estimation approach follows a multi-stage procedure. In the following, we describe for each instrumented variable how we proceed to obtain the respective instrumental variable that is used in the final estimation step whose results are reported in Table 5.

Quality We regress the quality variable on firm dummies. Specifically, we regress the quality ratings of 73 brands on 10 firm dummies. $\mathrm{R}^{2}$ amounts to .305 . The 
predicted values of this regression are used as instrumental variable for quality and $\log$ (quality) (after log transformation).

Order of entry We regress the order-of-entry variable on the variables listed in Table 9. To account for the ordinal nature of the dependent variable, we use an ordered probit model. Quality and market share are, however, themselves endogenous and need to be instrumented for use in the order-of-entry equation. We have already reported on the instruments used for quality. For market share, we regress the log of market share on brand dummies, the log of price, and the log of the stocks of own marketing expenditures, competitive marketing expenditures, and co-marketing expenditures. $\mathrm{R}^{2}$ amounts to .850 . We take the antilog of the predicted value in the last period observed for each brand as instrumental variable for the (expected) longterm market share. Table 9 shows the estimation results for the final order-of-entry regression. From this regression, we obtain the predicted order of entry for each brand which is further used as instrumental variable in the final estimation equation. Squared rank correlation (pseudo $\mathrm{R}^{2}$ ) of predicted with actual values amounts to .464 .

Long-term marketing expenditures We regress the stock of own marketing expenditures at the time of peak sales on the marketing expenditures of the fourth quarter of the preceding year. $\mathrm{R}^{2}$ amounts to .607 . The log of predicted values of this regression are used as observations for an instrumental variable for log(long-term marketing expenditures).

Number of competitors We regress the log of the number of competitors in a category on the log of the average number of competitors in this category in the remaining three countries. $\mathrm{R}^{2}$ amounts to .781 . The predicted values of this regression are used as observations for the instrumental variable in the final estimation step.

Table 9 Estimation results for order-of-entry equation (ordered probit model)

\begin{tabular}{|c|c|c|c|}
\hline & Expected sign & Coefficient & Standard Error \\
\hline Constant & & -1.54 & $(1.17)^{\mathrm{NS}}$ \\
\hline (Expected) long-term market share ${ }^{\mathrm{a}}$ & - & -7.30 & $(1.37)$ \\
\hline Quality $^{\mathrm{a}}$ & + & 2.73 & $(.681)$ \\
\hline Time taken to obtain drug approval & + & .242 & $(.047)$ \\
\hline Entry in home country & - & -.160 & $(.470)^{\mathrm{NS}}$ \\
\hline Net income prior to market entry & - & $-4.6 \times 10^{-4}$ & $\left(1.3 \times 10^{-4}\right)$ \\
\hline Firm size (no. of employees) prior to market entry & - & .003 & $(.003)^{\mathrm{NS}}$ \\
\hline Availability of co-marketing partner & - & .107 & $(.266)^{\mathrm{NS}}$ \\
\hline Speed of international market rollout & - & -.004 & $(.123)^{\mathrm{NS}}$ \\
\hline Log Likelihood & & -132.81 & \\
\hline McFadden's $\mathrm{R}^{2} /$ Pseudo $\mathrm{R}^{2}$ (squared rank correlation) & & $.218 / .464$ & \\
\hline No. of brands (observations) & & 73 & \\
\hline
\end{tabular}

$\mathrm{NS}=$ not significant $(p>.05)$. Details on variable operationalization may be obtained from the authors on request. Full sample of 73 brands used to explain order of entry

${ }^{a}$ Instrumental variables used 


\section{References}

Agarwal, R., \& Bayus, B. L. (2002). The market evolution and sales takeoff of product innovations. Management Science, 48(8), 1024-1041.

Ainslie, A., Drèze, X., \& Zufryden, F. (2005). Modeling movie lifecycles and market share. Marketing Science, 24(3), 508-517.

Alpert, F. H., \& Kamins, M. A. (1994). Pioneer brand advantage and consumer behavior: a conceptual framework and propositional inventory. Journal of the Academy of Marketing Science, 22(3), 244253.

Bass, F. M. (1969). A new product growth model for consumer durables. Management Science, 15, 215227.

Bauer, H. H., \& Fischer, M. (2000). Product life cycle patterns for pharmaceuticals and their impact on R\&D profitability of late mover products. International Business Review, 9(6), 703-725.

Bayus, B. L. (1998). An analysis of product lifetimes in a technologically dynamic industry. Management Science, 44(6), 763-775.

Berndt, E. R., Bui, L., Reily, D. R., \& Urban, G. L. (1995). Information, marketing, and pricing in the U.S. antiulcer drug market. American Economic Review, Papers and Proceedings, 85(2), 100-105.

Bodapati, A., \& Gupta, S. (2004). The recoverability of segmentation structure from store-level aggregate data. Journal of Marketing Research, 41(3), 351-364.

Boswijk, H. P., \& Franses, P. H. (2005). On the econometrics of the Bass diffusion model. Journal of Business and Economic Statistics, 23, 255-268.

Brockhoff, K. (1967). A test for the product life cycle. Econometrica, 35(3/4), 472-484.

Chintagunta, P. K., Erdem, T., Rossi, P. E., \& Wedel, M. (2006). Structural modeling in marketing: review and assessment. Marketing Science, 26(6), 604-616.

Cooper, L. G., \& Nakanishi, M. (1988). Market-share analysis: Evaluating competitive marketing effectiveness. Boston: Kluwer Academic.

Corstjens, M., Demeire, E., \& Horowitz, I. (2005). New product success in the pharmaceutical industry: how many bites at the cherry? Economics of Innovation and New Technology, 14(4), 319-331.

Cox, W. E. (1967). Product life cycles as marketing models. Journal of Business, 40(4), 375-384.

Datamonitor (2007). Orthovita: Cortoss could generate high sales in the spinal fracture market, http://www. datamonitor.com/companies/company/?pid=6FB42625-9E2A-4DB4-82B1-26875E2D5B7C\&nid= 1AE201D1-E6E5-4EAD-85F2-205968C4FA11\&type=CommentWire\&article=1 (Accessed at 1/22/2008).

Dhalla, N. K., \& Yuspeh, S. (1976). Forget the product life cycle concept! Harvard Business Review, 54 (1), 102-111.

Dubé, J. P., \& Manchanda, P. (2005). Differences in dynamic brand competition across markets: an empirical analysis. Marketing Science, 24(1), 81-95.

Fischer, M., \& Albers, S. (2010). Patient- or physician-oriented marketing: what drives primary demand for prescription drugs? Journal of Marketing Research, 47(1), 103-121.

Fok, D., \& Franses, P. H. (2007). Modeling the diffusion of scientific publications. Journal of Econometrics, 139, 376-390.

Franses, P. H. (2005). Diagnostics, expectations, and endogeneity. Journal of Marketing Research, 42(1), 27-29.

Gielens, K., \& Dekimpe, M. G. (2001). Do international entry decisions of retail chains matter in the long run? International Journal of Research in Marketing, 18(3), 235-259.

Gielens, K., \& Steenkamp, J. B. E. M. (2007). Drivers of consumer acceptance of new packaged goods: An investigation across products and countries. International Journal of Research in Marketing, 24 (2), 97-112.

Goldenberg, J., Libai, B., \& Muller, E. (2002). Riding the saddle: how cross-market communications can create a major slump in sales. Journal of Marketing, 66(2), 1-16.

Golder, P. N., \& Tellis, G. J. (1993). Pioneer advantage: marketing logic or marketing legend? Journal of Marketing Research, 30(2), 158-170.

Golder, P. N., \& Tellis, G. J. (1997). Will it ever fly? Modeling the takeoff of really new consumer durables. Marketing Science, 16(3), 256-270.

Golder, P. N., \& Tellis, G. J. (2004). Growing, growing, gone: cascades, diffusion, and turning points in the product life cycle. Marketing Science, 23(2), 207-218.

Grabowski, H., \& Vernon, J. (1990). A new look at the returns and risks to pharmaceutical R\&D. Management Science, 36(7), 804-821.

Greene, W. H. (2004). Econometric analysis (5th ed.). Upper Saddle River: Prentice Hall. 
Hahn, M., Park, S., Krishnamurthi, L., \& Zoltners, A. (1994). Analysis of new product diffusion using a four-segment trial-repeat model. Marketing Science, 13(3), 224-247.

Hauser, J. R., Tellis, G. J., \& Griffin, A. (2006). Research on innovation: a review and agenda for future research. Marketing Science, 25(6), 687-717.

Hill, R. C., \& Adkins, L. C. (2003). Collinearity. In B. H. Baltagi (Ed.), A companion to theoretical econometrics. Malden: Blackwell.

Horsky, D., \& Simon, L. L. (1983). Advertising and the diffusion of new products. Marketing Science, 2 (1), 1-18.

Kalyanaram, G., \& Urban, G. L. (1992). Dynamic effects of order-of-entry on market share, trial penetration, and repeat purchases for frequently purchased consumer goods. Marketing Science, 11(3), $235-250$.

Kalyanaram, G., Robinson, W. T., \& Urban, G. L. (1995). Order of market entry: established empirical generalizations, emerging empirical generalizations, and future research. Marketing Science, 14(3/2), G212-G221.

Kalyanaraman, G., \& Wittink, D. R. (1994). Heterogeneity in entry effets between nondurable consumer product categories. International Journal of Research in Marketing, 11(3), 219-231.

Kornelis, M., Dekimpe, M. G., \& Leeflang, P. S. H. (2008). Does competitive entry structurally change key marketing metrics. International Journal of Research in Marketing, 25(3), 173-182.

Kremer, S. T. M., Bijmolt, T. H. A., Leeflang, P. S. H., \& Wieringa, J. E. (2008). Generalizations on the effectiveness of pharmaceutical promotional expenditures. International Journal of Resesarch in Marketing, 25(4), 234-246.

Krishnan, T. V., Bass, F. M., \& Kumar, V. (2000). Impact of a late entrant on the diffusion of a new product/service. Journal of Marketing Research, 37(2), 269-278.

Leenders, A. A. M., \& Wierenga, B. (2008). The effect of the marketing-R\&D interface on new product performance: the critical role of resources and scope. International Journal of Research in Marketing, 25, 56-68.

Lieberman, M. B., \& Montgomery, D. B. (1988). First-mover advantages. Strategic Management Journal, 9, 41-58.

Lilien, G. L., Rao, A. G., \& Kalish, S. (1981). Bayesian estimation and control of detailing effort in a repeat purchase diffusion environment. Management Science, 27(5), 493-506.

Mahajan, V., Muller, E., \& Bass, F. M. (1990). New product diffusion models in marketing: a review and directions for research. Journal of Marketing, 54(1), 1-26.

Manchanda, P., Wittink, D. R., Ching, A., Cleanthous, P., Ding, M., Dong, X. J., et al. (2005). Understanding firm, physician and consumer choice behavior in the pharmaceutical industry. Marketing Letters, 16(3/4), 293-308.

McAlister, L., \& Pessemier, E. (1982). Variety seeking behavior: an interdisciplinary review. Journal of Consumer Research, 9(3), 311-322.

Neelameghan, R., \& Chintagunta, P. K. (2004). Modeling and forecasting the sales of technology products. Quantitative Marketing \& Economics, 2(3), 195-232.

Obeid, I., \& Vine, P. (2005). Pharmaceutical industry: changing paradigms, changing opportunities. EJHPJournal, 11(4), 9. Available at www.eahponline.org/upload/ejhp/InthisIssue78-79.pdf.

Osinga, E. C., Leeflang, P. S. H., \& Wieringa, J. E. (2010). Early marketing matters. Journal of Marketing Research, 47(1), 173-185.

Polli, R., \& Cook, V. J., Jr. (1969). Validity of the product life cycle. Journal of Business, 42(4), 385-400.

Prins, R., \& Verhoef, P. C. (2007). Marketing communication drivers of adoption timing of a new EService among existing customers. Journal of Marketing, 71(2), 169-183.

Rao, A. G., \& Masataka, Y. (1988). Forecasting with a repeat purchase diffusion model. Management Science, 34(6), 734-752.

Robinson, W. T., \& Fornell, C. (1985). Sources of market pioneer advantages in consumer goods industries. Journal of Marketing Research, 22(3), 305-317.

Rogers, E. M. (1995). Diffusion of innovations (4th ed.). New York: The Free.

Schmid, E. A., \& Smith, D. A. (2002). Discovery, innovation and the cyclical nature of the pharmaceutical business. Drug Discovery Today, 7(10), 563-568.

Shankar, V., Carpenter, G. S., \& Krishnamurthi, L. (1998). Late mover advantage: how innovative late entrants outsell pioneers. Journal of Marketing Research, 35(1), 54-70.

Shankar, V., Carpenter, G. S., \& Krishnamurthi, L. (1999). The advantages of entry in the growth stage of the product life cycle: an empirical analysis. Journal of Marketing Research, 36(2), 269-276.

Simon, H. (1979). Dynamics of price elasticities and brand life cycles: an empirical study. Journal of Marketing Research, 16(4), 439-452. 
Srivastava, R. K., Shervani, T. A., \& Fahey, L. (1998). Market based assets and shareholder value: a framework for analysis. Journal of Marketing, 62(1), 2-18.

Steenkamp, J. B. E. M., \& Gielens, K. (2003). Consumer and market drivers of the trial probability of new consumer packaged goods. Journal of Consumer Research, 30(3), 368-384.

Stremersch, S., \& Tellis, G. J. (2004). Understanding and managing growth of international new products. International Journal of Research in Marketing, 21(4), 421-438.

Stremersch, S., \& van Dyck, W. (2009). Marketing of the life sciences: a new framework and research agenda for a nascent field. Journal of Marketing, 73, 4-30.

Suresh, P., Basu P. K., \& Venkatsasbramanian, V. (2006). Impact of improving pharmaceutical product development and manufacturing. Presentation for AICHE 2006, Purdue University.

Tellis, G. J., \& Johnson, J. (2007). The value of quality. Marketing Science, 26(6), 758-773.

Tellis, G. J., Stremersch, S., \& Yin, E. (2003). The international takeoff of new products: the role of economics, culture, and country innovativeness. Marketing Science, 22(2), 188-208.

Tradingmarkets.com (2007). Shares of Salix pharmaceuticals tumble; downgraded to sell at Piper Jaffray, available at http://www.tradingmarkets.com/.site/news/Stock\%20News/948264/ (Accessed at 1/22/2008).

Urban, G. L., Carter, T., Gaskin, S., \& Mucha, Z. (1986). Market share rewards to pioneering brands: an empirical analysis and strategic implications. Management Science, 32(6), 645-659.

Venkataraman, S., \& Stremersch, S. (2007). The debate on influencing doctors' decisions: are drug characteristics the missing link? Management Science, 53(11), 1688-1701.

von Bertalanffy, L. (1957). Quantitative laws in metabolism and growth. Quarterly Review of Biology, 32, 217-231.

Zhang, J., \& Narasimhan, C. (2000). Market entry strategy under firm heterogeneity and symmetric payoffs. Marketing Science, 19(4), 313-327. 